\title{
Simulations of the Northern Hemisphere through the last glacial-interglacial cycle with a vertically integrated and a three-dimensional thermomechanical ice-sheet model coupled to a climate model
}

\author{
R. Calov, ${ }^{1 *}$ I. Marsiat ${ }^{2}$ \\ ${ }^{1}$ Technische Universität Darmstadt, Institut für Mechanik III, Hochschulstraße 1, D-64289 Darmstadt, Germany \\ ${ }^{2}$ Department of Meteorology, University of Reading, 2 Earley Gate, Whiteknights, P.O. Box 243, Reading RG6 6BB, England
}

\begin{abstract}
We present simulations of the Northern Hemisphere land ice through the last glacial-interglacial cycle with a vertically integrated ice-sheet model and a three-dimensional thermomechanical ice-sheet model. Both models are coupled asynchronously to the zonally averaged Louvain-la-Neuve climate model, which includes simplified treatments of the atmosphere, ocean and sea ice. The two-dimensional vertically integrated ice-sheet model, which contains no thermomechanical coupling, was developed in spherical coordinates (Marsiat, 1994). The three-dimensional thermomechanical icesheet model was developed using the two-dimensional vertically integrated model as source.

We compare results of the vertically integrated with those of the thermomechanical ice-sheet model. In the thermomechanical model the deformation properties of ice depend on the temperature within the ice and the enhancement factor; the latter is introduced to model, in a simplified approach, the different flow properties of Pleistocene and Holocene ice due to varying dust content. The computations with the thermomechanical model show that the growth and decay of the Northern Hemisphere ice sheets can be modelled with a common enhancement factor for all ice sheets. It is shown that there are model set-ups for the thermomechanical model yielding temporal developments of the total ice volume comparable to those of the vertically integrated model. Furthermore, we demonstrate that for the coupled climate/cryosphere system the total ice volume depends considerably on the enhancement factor.
\end{abstract}

\section{INTRODUCTION}

This paper is a study of the Northern Hemisphere ice sheets. Other such studies have been undertaken by Deblonde and Peltier (1993), Marsiat (1994), Peltier and Marshall (1995), Huybrechts and T'siobbel (1997) and Tarasov and Peltier (1997). Deblonde and Peltier (1993) used a two-dimensional vertically integrated ice-sheet model (with a different relation for averaged horizontal velocity than our twodimensional model), which is coupled with a seasonal energy-balance model with an additional term treating the influence of North Atlantic heat flux, to simulate the last glacial-interglacial cycle. Their approach was extended by Peltier and Marshall (1995) in order to investigate the role of a possible marine instability of the Laurentide ice sheet as well as the influence of terrigenous dust on the ablation area for decay of the Northern Hemisphere ice sheets. Tarasov and Peltier (1997) continued the studies of Peltier and Marshall, introducing further developments to their coupled model (e.g. changed parameterizations of precipitation and ablation). Huybrechts and T'siobbel (1997)

* Present address: Potsdam Institute for Climate Impact Research, P.O. Box 6012 03, D-14412 Potsdam, Germany. ttps://doi.org/10.3189/1998AoG27-1-169-176 Published online by Cambridge University Press simulated the steady state of the Northern Hemisphere ice sheets at the Last Glacial Maximum (LGM), using a climate model after Sellers (1983) as forcing.

We present simulations of the Northern Hemisphere ice sheets during the last glacial-interglacial cycle with the continental surface and ice-sheet model (CIM; Marsiat, 1994) and, alternatively, the continental surface and thermomechanical ice-sheet model (CTIM). Both models include the evolution of ice thickness formulated in spherical coordinates. The CTIM additionally includes an evolution equation of the ice temperature, the three-dimensional velocity, basal sliding and temperature-viscosity coupling using the Arrhenius relation according to Paterson (1981). This new thermomechanical ice-sheet model is similar to other models (Huybrechts and Oerlemans, 1988; Calov and Hutter, 1996; Greve, 1997; Ritz and others, 1997). The CIM uses a vertically integrated representation of the ice velocity and the diffusivity. CIM and CTIM are each coupled with the Louvain-la-Neuve (LLN) climate model which simulates several components of the climate system (e.g. atmosphere, ocean, sea ice) in simplified approaches. The LLN two-dimensional climate model is latitude- and altitude-dependent. Its domain covers the Northern Hemisphere with a resolution of $5^{\circ}$ in latitude. Atmospheric dynamics are represented by a zonally averaged quasi-geostrophic model, 
including parameterization of the meridional transport of quasi-geostrophic potential vorticity and of the Hadley sensible-heat transport. The atmosphere interacts with the other components of the climate through vertical fluxes of momentum, heat and water. The model explicitly incorporates detailed radiative-transfer schemes, surface-energy balances, and snow and sea-ice budgets. The vertical profile of the upper-ocean temperature is computed by an integral mixed-layer model which takes into account the meridional convergence of heat. Sea ice is represented by a thermodynamic model including leads and lateral accretion. The CTIM three-dimensional model combines three parts: a model representing the ice thermomechanics; a model representing the depression of the asthenosphere under the weight of the ice; and the mass-balance evaluation over the ice sheet and the continents.

The main objective of this paper is to show the influence of thermomechanical ice-sheet modelling on the ice cover through the last glacial cycle and to elucidate the role of the enhancement factor on the ice cover if the response of the climate system is included.

\section{THE ICE-SHEET MODELS GIM AND GTIM IN SPHERICAL GOORDINATES}

The details of transformation to spherical coordinates are not shown here. We start with the transformation after Marsiat (1994),

$$
\boldsymbol{V}_{\mathrm{H}}=\frac{\cos \phi}{r_{0}} \boldsymbol{v}_{\mathrm{H}}, \quad V_{\mathrm{r}}=v_{\mathrm{r}}, \quad \boldsymbol{Q}=\frac{\cos \phi}{r_{0}} \boldsymbol{q},
$$

applied to the horizontal velocity $\boldsymbol{v}_{\mathrm{H}}=v_{\lambda} \hat{\boldsymbol{e}}_{\lambda}+v_{\phi} \hat{\boldsymbol{e}}_{\phi}$ the vertical velocity $v_{\mathrm{r}}$ and the mass flux $\boldsymbol{q}=q_{\lambda} \hat{\boldsymbol{e}}_{\lambda}+q_{\phi} \hat{\boldsymbol{e}}_{\phi}$. The thickness evolution equation reads

$$
\frac{\partial H}{\partial t}=-\left(\frac{1}{1-\mu^{2}} \frac{\partial Q_{\lambda}}{\partial \lambda}+\frac{\partial Q_{\mu}}{\partial \mu}\right)+M
$$

where $\phi$ is latitude, $\lambda$ is longitude, $\mu=\sin \phi$, and $r_{0}$ is the Earth's radius, and the temperature evolution yields

$$
\frac{\partial T}{\partial t}+V_{\mathrm{r}} \frac{\partial T}{\partial r}+\frac{V_{\lambda}}{1-\mu^{2}} \frac{\partial T}{\partial \lambda}+V_{\mu} \frac{\partial T}{\partial \mu}=\kappa \frac{\partial^{2} T}{\partial r^{2}}+d,
$$

with the dissipation term

$$
\begin{aligned}
d= & \frac{2 \rho^{n} g^{n+1}}{c r_{0}^{n+1}} E A\left(T^{\prime}\right)(h-r)^{n+1} \\
& {\left[\frac{1}{1-\mu^{2}}\left(\frac{\partial h}{\partial \lambda}\right)^{2}+\left(1-\mu^{2}\right)\left(\frac{\partial h}{\partial \mu}\right)^{2}\right]^{\frac{n+1}{2}}, }
\end{aligned}
$$

where $H$ is the ice thickness, $h$ is the surface elevation, $r$ is the vertical direction, $Q_{\lambda}$ and $Q_{\mu}$ are the components of the transformed mass flux $\boldsymbol{Q}=Q_{\lambda} \hat{\boldsymbol{e}}_{\lambda}+Q_{\mu} \hat{\boldsymbol{e}}_{\phi}, V_{\lambda}$ and $V_{\mu}$ are the horizontal components of the transformed velocity $\boldsymbol{V}_{\mathrm{H}}=V_{\lambda} \hat{\mathbf{e}}_{\lambda}+V_{\mu} \hat{\mathbf{e}}_{\phi}, V_{r}$ is the transformed vertical velocity, $M$ is the surface mass balance, $E$ is the enhancement factor, $\rho$ is the density of ice, $g$ is the acceleration of gravity, $\kappa$ is thermal diffusivity and $c$ is the specific heat. The constant $n=3$ is the power exponent of Glen's flow law. For the rate factor $A\left(T^{\prime}\right)$ the Arrhenius relation, with values given by Paterson (1981) and the homologous temperature $T^{\prime}$, according to $T^{\prime}=T+a \rho g(h-r)$ with Clausius-Clapeyron constant $a=7.42 \times 10^{-5} \mathrm{~K}(\mathrm{kPa})^{-1}$, is used.
The boundary conditions at the surface and at the base are

$$
\left.T\right|_{r=h(\lambda, \mu, t)}=T_{\mathrm{a}}(\lambda, \mu, t)
$$

and

$$
\left.\chi \frac{\partial T}{\partial r}\right|_{r=b(\lambda, \mu)}+\boldsymbol{\tau}_{b}^{*} \cdot \boldsymbol{v}_{\mathrm{b}}=-G,
$$

respectively, where $T_{\mathrm{a}}$ is the surface temperature, $G$ is the geothermal heat $\left(G=42 \times 10^{-3} \mathrm{~mW} \mathrm{~m}^{-2}\right), \boldsymbol{\tau}_{\mathrm{b}}^{*}$ is the basal shear traction, $\mathbf{v}_{\mathrm{b}}$ is the sliding velocity and $\chi$ is the heat conduction $\left(\chi=2.1 \mathrm{~W} \mathrm{~m}^{-1} \mathrm{~K}^{-1}\right)$.

The transformed horizontal velocity is

$$
\begin{array}{r}
\boldsymbol{V}_{\mathrm{H}}(r, \lambda, \mu, t)=\boldsymbol{V}_{\mathrm{H}}(b)-C(r, \lambda, \mu, t) \\
\left(\hat{\boldsymbol{e}}_{\lambda} \frac{\partial h}{\partial \lambda}+\hat{\boldsymbol{e}}_{\phi}\left(1-\mu^{2}\right) \frac{\partial h}{\partial \mu}\right),
\end{array}
$$

where

$$
\begin{aligned}
C(r, \lambda, \mu, t)= & \frac{2(\rho g)^{n}}{r_{0}^{n+1}} \\
& {\left[\frac{1}{1-\mu^{2}}\left(\frac{\partial h}{\partial \lambda}\right)^{2}+\left(1-\mu^{2}\right)\left(\frac{\partial h}{\partial \mu}\right)^{2}\right]^{\frac{n-1}{2}} } \\
& \int_{b}^{r} E A\left[T^{\prime}\left(r^{\prime}\right)\right]\left(h-r^{\prime}\right)^{n} \mathrm{~d} r^{\prime}
\end{aligned}
$$

$b$ is the bottom height and $V_{\mathrm{H}}(b)$ is the (transformed) sliding velocity. The vertical velocity is

$$
V_{\mathrm{r}}(r, \lambda, \mu, t)=V_{\mathrm{r}}(b)-\int_{b}^{r}\left(\frac{1}{1-\mu^{2}} \frac{\partial V_{\lambda}}{\partial \lambda}+\frac{\partial V_{\mu}}{\partial \mu}\right) \mathrm{d} r^{\prime} .
$$

We use a Weertman-type sliding law (Weertman, 1964) with exponents after Calov and Hutter (1996). With this it follows, with the transformation $(1)_{1}$ for the sliding velocity,

$$
\begin{aligned}
\boldsymbol{V}_{\mathrm{H}}(b)= & -c_{\mathrm{s}} \frac{\rho g H}{r_{0}^{4}}\left[\frac{1}{1-\mu^{2}}\left(\frac{\partial h}{\partial \lambda}\right)^{2}+\left(1-\mu^{2}\right)\left(\frac{\partial h}{\partial \mu}\right)^{2}\right] \\
& {\left[\hat{\boldsymbol{e}}_{\lambda} \frac{\partial h}{\partial \lambda}+\hat{\boldsymbol{e}}_{\phi}\left(1-\mu^{2}\right) \frac{\partial h}{\partial \mu}\right] }
\end{aligned}
$$

where for the sliding parameter the value $c_{\mathrm{s}}=2.13 \times 10^{-7}$ $\mathrm{m}^{2} \mathrm{~s} \mathrm{~kg}^{-1}$ applies. In the model, sliding applies only if the base is at the melting point, i.e. the homologous basal temperature equals zero.

We introduce the diffusivity $D$ as

$$
\boldsymbol{Q}=\int_{b}^{h} \boldsymbol{V}_{\mathrm{H}} \mathrm{d} r=-D\left[\hat{\boldsymbol{e}}_{\lambda} \frac{\partial h}{\partial \lambda}+\hat{\boldsymbol{e}}_{\phi}\left(1-\mu^{2}\right) \frac{\partial h}{\partial \mu}\right] .
$$

Comparison with Equations (6), (7) and (9) yields

$$
\begin{aligned}
D(r, \lambda, \phi)= & c_{\mathrm{s}} \frac{\rho g}{r_{0}^{4}} H^{2} l_{\mathrm{H}}+2 \frac{(\rho g)^{n}}{r_{0}^{4}} l_{\mathrm{H}}^{\frac{n-1}{2}} \\
& \int_{b}^{h} \int_{b}^{r} E A\left[T^{\prime}\left(r^{\prime}\right)\right]\left(h-r^{\prime}\right)^{n} \mathrm{~d} r^{\prime} \mathrm{d} r,
\end{aligned}
$$

where

$$
l_{\mathrm{H}}=\frac{1}{1-\mu^{2}}\left(\frac{\partial h}{\partial \lambda}\right)^{2}+\left(1-\mu^{2}\right)\left(\frac{\partial h}{\partial \mu}\right)^{2} .
$$

Since sliding only applies if the basal temperature $T_{\mathrm{b}}$ is at the melting point, the sliding parameter $c_{\mathrm{s}}$ in Equation (11) is zero for $T_{\mathrm{b}}<0$ ("freezing").

Equations (3)-(11) together with the thickness-evolution equation (2) describe the spherical thermomechanical model (CTIM). For the vertically integrated model (CIM) 
the temperature dependence of the rate factor is ignored $\left(A\left(T^{\prime}\right) \rightarrow A\right)$ and the sliding parameter $c_{\mathrm{s}}$ is zero everywhere. Thus, temperature evolution in the ice sheet is neglected for the vertically integrated model. For this nonthermomechanical case the integrals in Equation (11) can be solved analytically,

$$
\begin{aligned}
D(\lambda, \phi)= & \frac{2 A E}{5}(\rho g)^{3} \frac{H^{5}}{r_{0}^{4}} \\
& {\left[\frac{1}{1-\mu^{2}}\left(\frac{\partial h}{\partial \lambda}\right)^{2}+\left(1-\mu^{2}\right)\left(\frac{\partial h}{\partial \mu}\right)^{2}\right] . }
\end{aligned}
$$

Both ice-sheet models model the reaction of the asthenosphere to the varying ice load and apply an energy-balance model for the computation of the snow melting at the icesheet surface.

The model equations are solved on a staggered grid with a stretched $\sigma$ transformation

$$
r=b+H \frac{\mathrm{e}^{a_{s} \zeta}-1}{\mathrm{e}_{\mathrm{s}}^{a}-1}, \quad a_{\mathrm{s}}=2,
$$

in the vertical. The ice-thickness evolution equation is solved semi-implicitly with an alternating-direction-implicit scheme. In the temperature-evolution equation vertical derivatives are discretized implicitly, and horizontal derivatives are taken explicitly, with upwind discretisation of the advection term. The horizontal resolution is $0.7^{\circ} \times 0.7^{\circ}$ $(257 \times 256$ gridpoints $)$ and the vertical grid spacing is $\Delta \zeta=1 / 15$ (16 gridpoints). The model performs different time-steps for the thickness evolution $(\Delta t=10$ years $)$ and the temperature evolution $\left(\Delta t_{\text {temp }}=100\right.$ years $)$.

\section{THE GOUPLING OF THE ICE-SHEET MODELS AND THE LLN GLIMATE MODEL}

The LLN model is coupled asynchronously to the vertically integrated CIM or the thermomechanical CTIM. The LLN model includes simplified treatments of the atmosphere, the ocean, the sea ice, the snow-free land and the snowfield. The
CIM/CTIM uses the following zonally averaged quantities computed by the LLN model:

solar and longwave downward fluxes

$500 \mathrm{mb}$ level temperature

zonal annual mean precipitation

a term representing the contribution of the diurnal and synoptic temperature variance to the sensible-heat flux.

Inversely, the CIM/CTIM provides the LLN model with the spatial extent and mean altitude of the Northern Hemisphere ice sheets.

It is assumed that at the $500 \mathrm{mb}$ level, for all the points situated at the same latitude, the atmosphere is identical to the zonal mean computed by the LLN model. Local radiative fluxes and temperature at the top of the boundary layer are then interpolated from the zonal means, including local characteristics such as altitude. Details of the interpolation process are given in Marsiat (1994).

The LLN model is calculated to steady state, which is reached after 15 years. The zonally averaged climate quantities are input of CIM/CTIM and interpolated to the latitude-longitude grid of CIM/CTIM. After that, CIM or CTIM calculates the change of ice cover over 1000 years. This new ice cover is provided to the LLN model for calculation of a new steady state defining the forcing for the next 1000 years integration of CIM/CTIM. A detailed description of the LLN model can be found in Gallée and others (1991); for the coupling between the LLN model and CIM see Marsiat (1994).

\section{THE GLACIAL-INTERGLACIAL GYGLE OF THE NORTHERN HEMISPHERE}

We first introduce two runs with the CIM coupled to the LLN climate model. Run 1 repeats a paleoclimatic simulation of Marsiat (1994) (for the vertically integrated temperature-independent simulation, see Equation (12)) with a

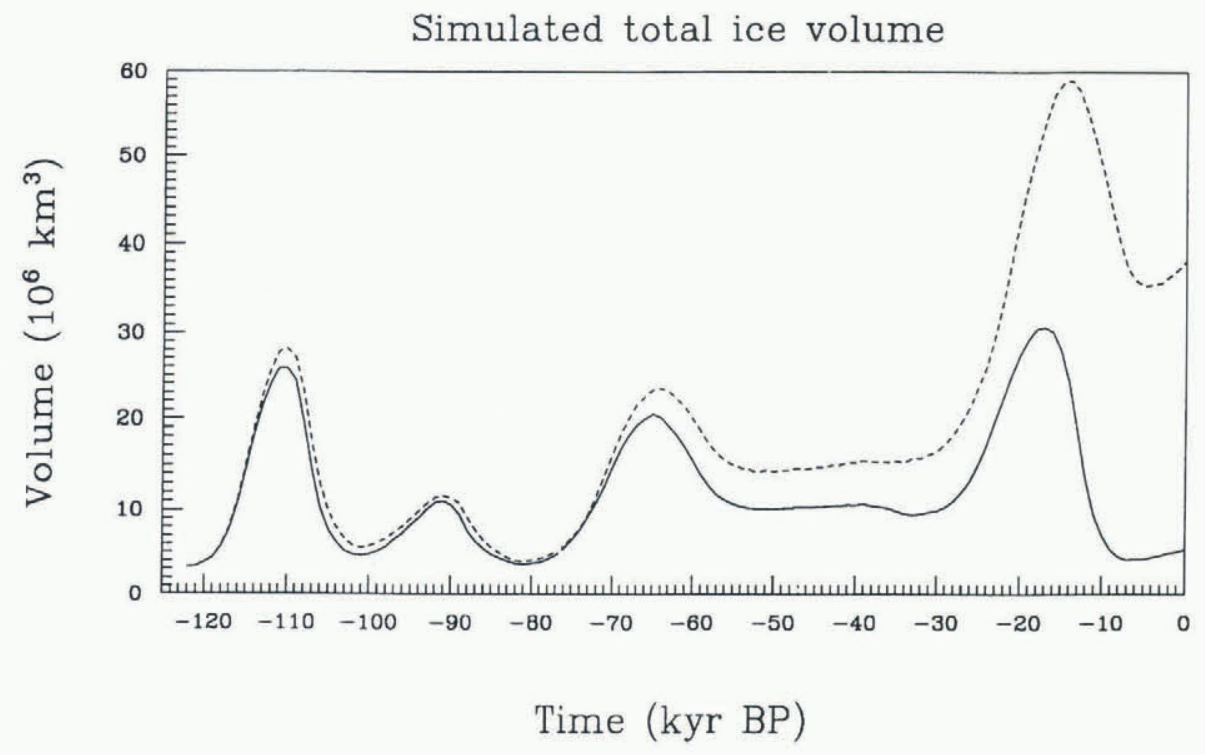

Fig. 1. Total ice volume of the Northern Hemisphere for run 1 (full line) and run 2 (short dashed line). The computations were performed with the vertically integrated ice-sheet model (CIM) using various enhancement factors for the different ice sheets according to Equation (14) (run 1), and a common enhancement factor $E=1$ for all ice sheets ( run 2). 

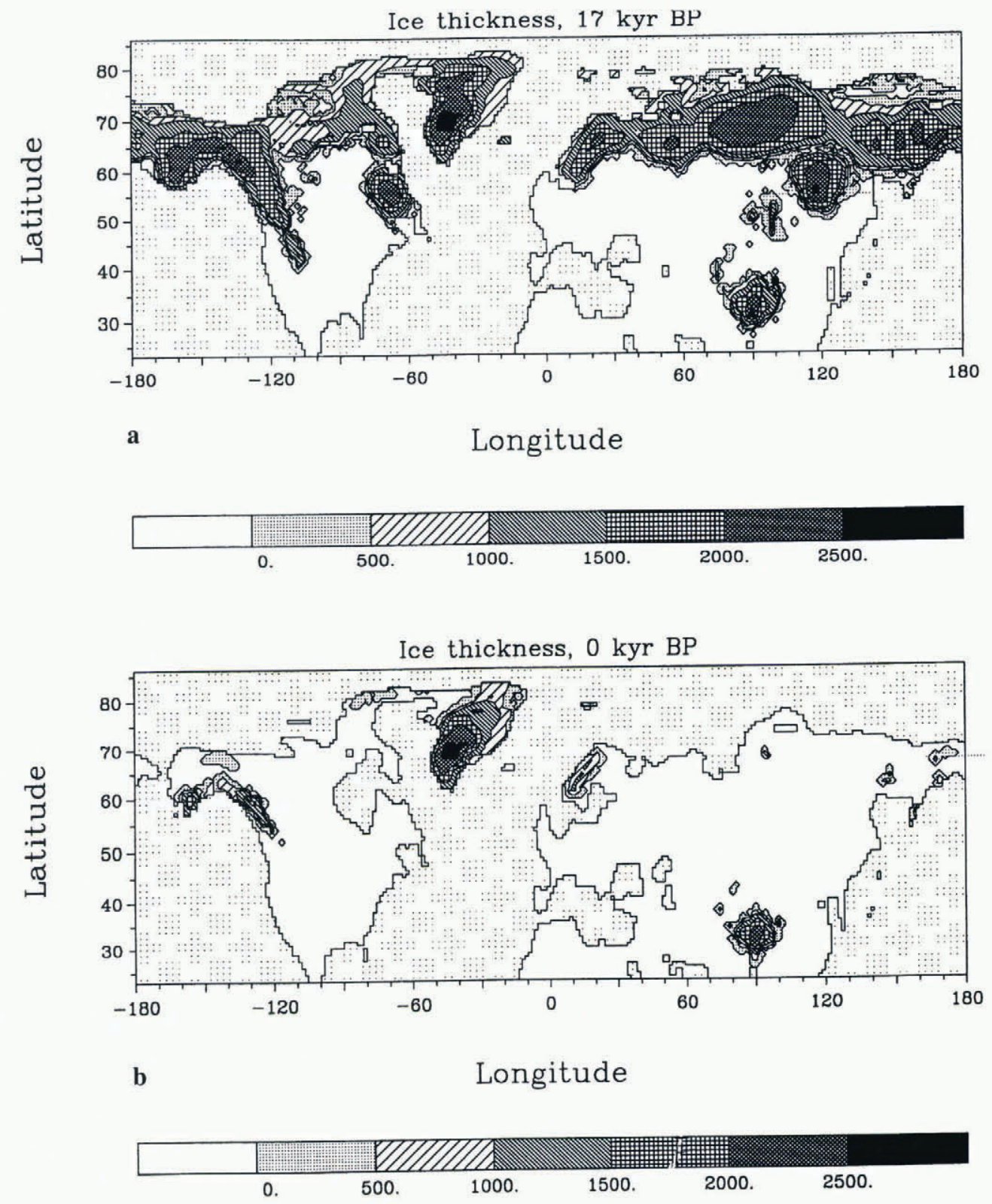

Fig. 2. Shading patterns of the ice thickness of the Northern Hemisphere in meters, showing snapshots of the simulated glacialinterglacial cycle at the LGM ( $a$ ) and at present $(b)$ for run 1 .

rate factor $A=3 \times 10^{-16} \mathrm{a}^{-1} \mathrm{~Pa}^{-3}$ and an ice density $\rho=886 \mathrm{~kg} \mathrm{~m}^{-3}$. For the enhancement factor,

$$
E=\left\{\begin{array}{l}
1 \text { for Greenland, Tibet, Cordillera } \\
4 \text { for Laurentide, Eurasia, Siberia }
\end{array}\right.
$$

is chosen. For run 2 the enhancement factor $E=1$ is used for the whole Northern Hemisphere, while the remaining set-up is as for run 1. CIM/LLN models are integrated (asynchronously) for 122000 years.

Figure 1 compares the temporal development of the simulated total ice volume of the Northern Hemisphere for runs 1 and 2. The total ice volume of run 1 corresponds well with observations (see Marsiat, 1994). While the difference between the total ice volume of runs 2 and 1 is relatively small in the time-span from 122 to $65 \mathrm{ka} \mathrm{BP}$, it increases considerably after $65 \mathrm{ka}$ BP. At the modelled LGM (17 ka BP) the total ice volume of run 2 is more than twice that of run 1. The simulated present-day ice volume of run 2 differs greatly from observations.

Figure 2 displays the simulated ice thickness at $17 \mathrm{ka} \mathrm{BP}$ and the present for run 1 . At $17 \mathrm{ka} \mathrm{BP}$ (Fig. 2a), there are large ice sheets in North America and Eurasia; the whole Tibetan Plateau is glaciated; the ice margin of the Laurentide ice sheet does not extend far enough south; and there is extended glaciation in Siberia, contrary to the findings of CLIMAP (1981), although a smaller Siberian glaciation was found by Tushingham and Peltier (1991). Today's simulated ice thickness (Fig. 2b) corresponds relatively well with observations. The great ice sheets have disappeared, though there is still some land ice left. The survival of the Greenland ice sheet corresponds to reality, but the modelled present glaciation of the whole Tibetan Plateau is obviously false. The minor present glaciation of the Rocky Mountains and of north Scandinavia is nearly sub-grid scale. When judging these results one must remember that the whole last glacial cycle with minor tuning is modelled in this approach. The build-up and decay of the Northern Hemisphere's land ice is discussed in detail by Marsiat (1994). The reason for the overall minor misfit to observations could be the zonally averaged climate model.

The strong sensitivity of CIM and the LLN model to the enhancement factor is illustrated dramatically by the ice 

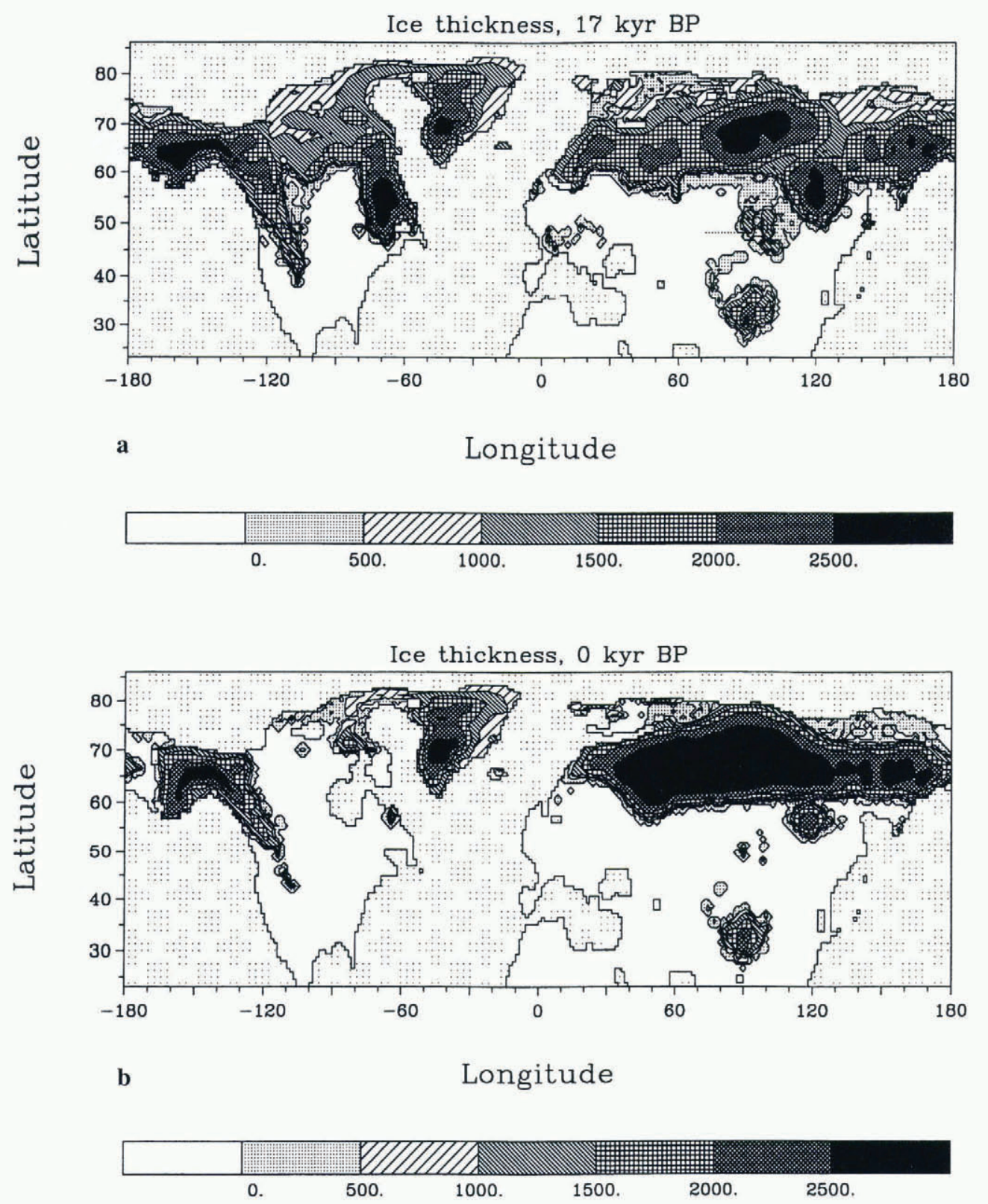

Fig. 3. As in Figure 2, but for run 2.

thickness from run 2 (see Fig. 3). At the modelled LGM (17 ka BP; Fig. 3a) the glaciated area of North America and Eurasia is more extended than for run 1 (Fig. 2a). The ice thickness of the Eurasian ice sheet increases by $500 \mathrm{~m}$. At the present time the simulated Eurasian ice sheet (Fig. 3b) is still there, and its ice is even thicker than at $17 \mathrm{ka} \mathrm{BP}$. A possible explanation of this behaviour is as follows: The lowering of the enhancement factor leads to enlarged ice thickness, because the flow of ice is hampered. The thicker ice has an enlarged accumulation area, because the surface

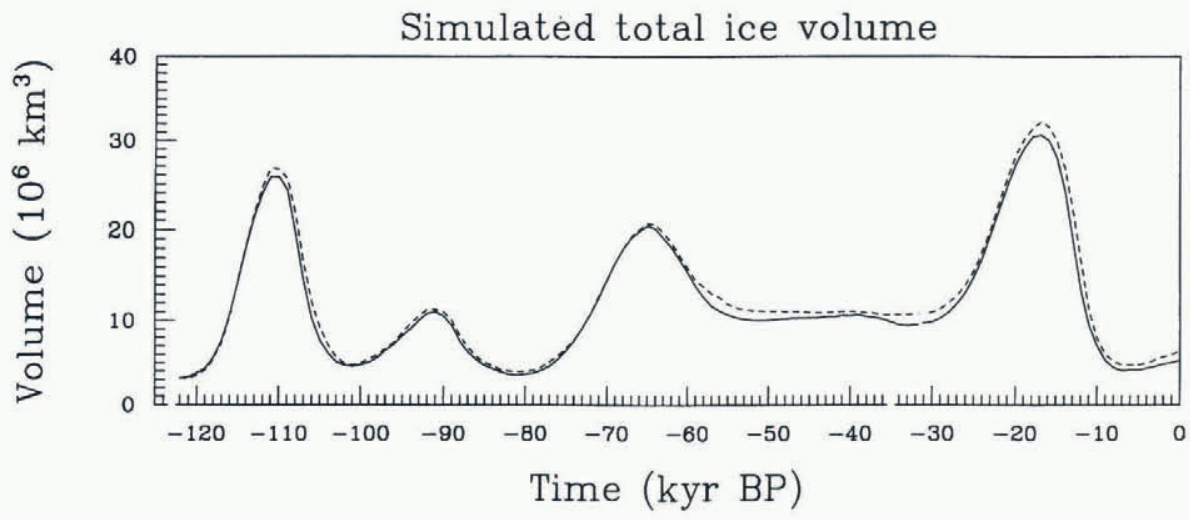

Fig. 4. Total ice volume of the Northern Hemisphere for the glacial-interglacial cycle, computed with the vertically integrated icesheet model (run 3, full line) and the thermomechanical ice-sheet model (run 4, short dashed line). 

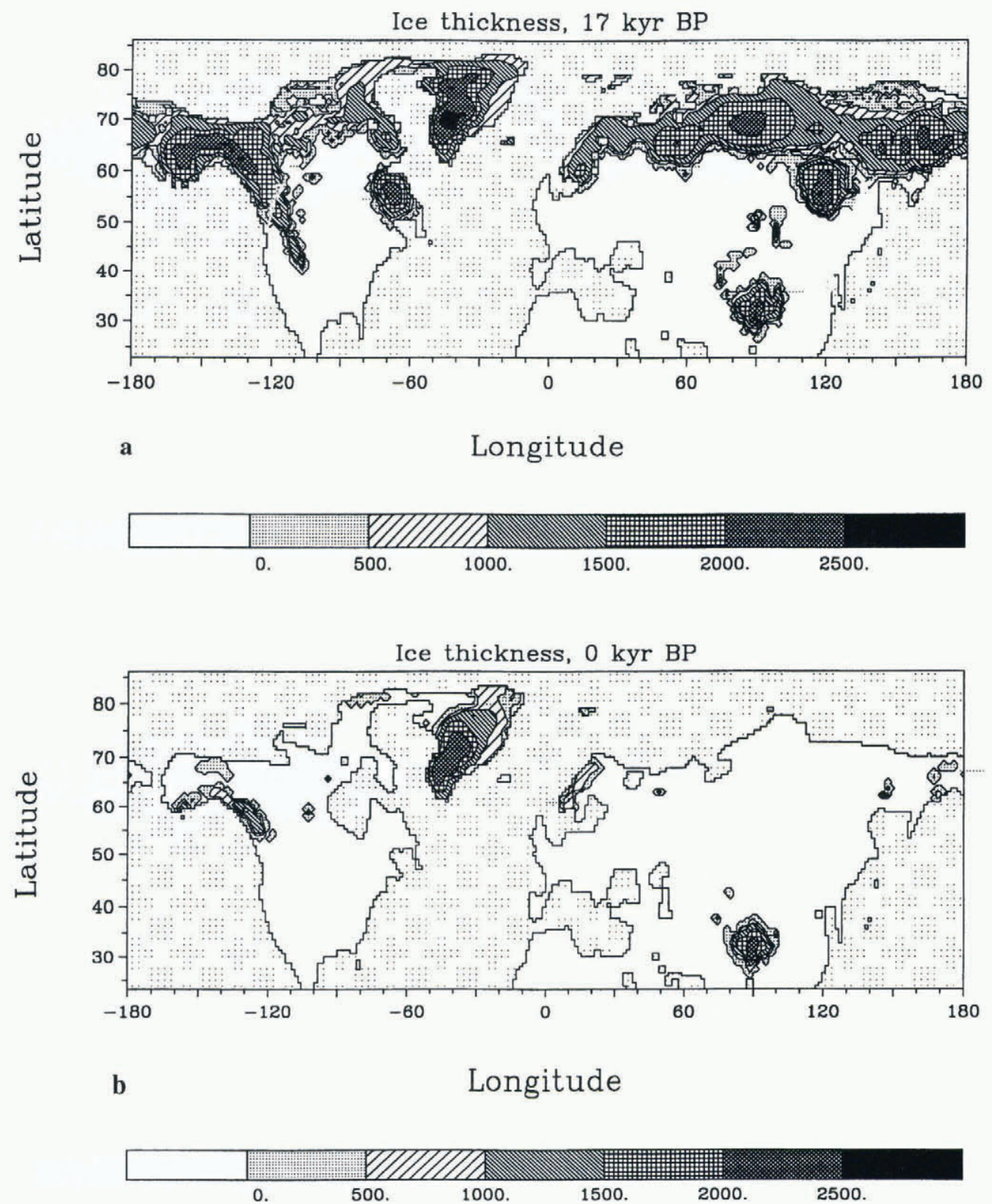

Fig. 5. Shading patterns of the ice thickness of the Northern Hemisphere in meters, showing snapshots of the simulated glacialinterglacial cycle at the LGM (a) and at present (b) for run 3. Computations were performed with the vertically integrated icesheet model (CIM).

slope at the ice margins is steeper than for thinned ice. For thicker ice there is a larger part of the surface which reaches higher and thus colder parts of the atmosphere. There is an increase of ice area for thicker ice, as can be seen by comparing Figures $2 \mathrm{a}$ and $3 \mathrm{a}$. Why can thicker ice now spread over the continent? (Before, I wrote that the lowered enhancement factor hampers the flow.) The thicker ice (and the steeper surface slope) must increase the ice velocities to enable more spreading. In addition, large ice area leads to higher planetary albedo and colder climate. Thus a positive feedback contributes to enlarged ice thickness. During the Holocene, when a warmer climate prevails, the thicker ice takes longer to melt if the same melting rate is assumed. These runs demonstrate the importance of the interaction of ice dynamics and climate.

We now compare the vertically integrated ice-sheet model (CIM) with the thermomechanical one (CTIM). For the computation with CIM and the LLN model (run 3 ) a model set-up as for run 1 is chosen, but with a rate factor $A=2.769 \times 10^{-16} \mathrm{a}^{-1} \mathrm{~Pa}^{-3}$ and an ice density $\rho=910 \mathrm{~kg} \mathrm{~m}^{-3}$.
For the thermomechanical simulation with CTIM and the LLN model (run 4) the rate factor $A\left(T^{\prime}\right)$ is now temperature-dependent, and Equations (2)-(11) apply. The density is as for run 3, and the enhancement factor is $E=3$. Figure 4 compares the simulated total ice volume of runs 3 and 4 . Overall, there are only minor differences in the temporal development of ice volume. Run 4 yields about $2 \times 10^{6} \mathrm{~km}^{3}$ more ice at the LGM, and at the present there is an increase of approximately $1 \times 10^{6} \mathrm{~km}^{3}$ for run 4 compared with run 3 . Let us now compare the Northern Hemisphere ice-thickness distribution of run 3 (Fig. 5) and run 4 (Fig. 6) at 17 and $0 \mathrm{ka}$ BP. The ice-covered area is roughly the same for both runs both at $17 \mathrm{ka} \mathrm{BP}$ and today, but there are differences in the ice-thickness distribution. At the LGM the Cordilleran and Laurentide ice sheets are thicker for run 4 than for run 3 (see the black shading patterns of the Cordilleran and the $1000-1500 \mathrm{~m}$ shading patterns of the Laurentide ice sheet). The thickness patterns of the Eurasian ice sheet show marked differences, the pattern for run 4 being relatively irregular. For both runs 3 and 4, there is a nearly continuous 

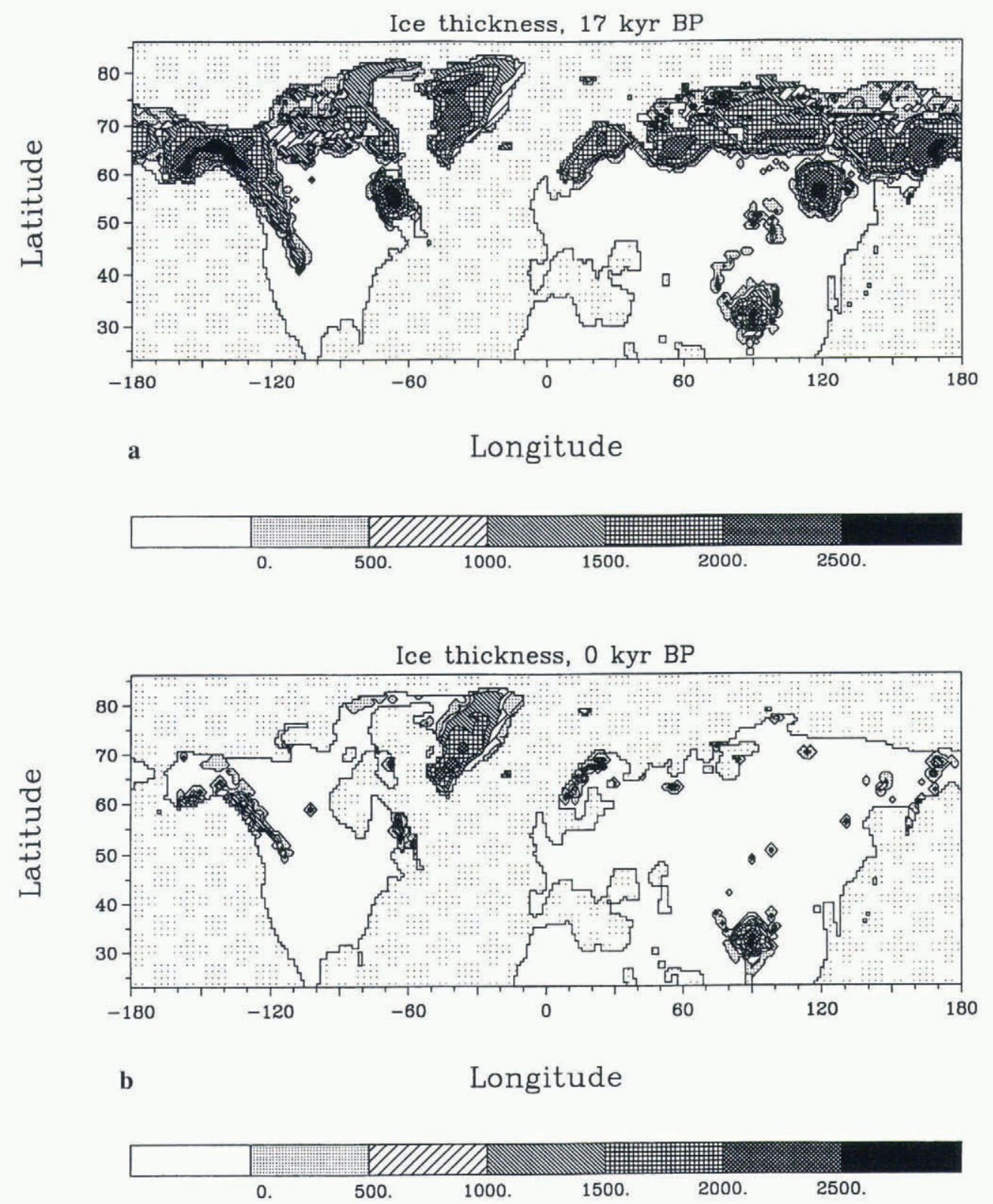

Fig. 6. As in Figure 5, but using the thermomechanical ice-sheet model (CTIM) for the glacial-interglacial simulation.

Siberian ice sheet. The Scandinavian ice sheet is clearly separated from the Eurasian ice sheet for run 4 but not for run 3. The maximum thickness of the Scandinavian and Siberian ice sheets for run 4 is larger than for run 3, but at $65^{\circ} \mathrm{N}, 90^{\circ} \mathrm{W}$ the elevation of the dome of run 3 is the larger. The thickness patterns of the Greenland ice sheet for runs 3 and 4 are also different: the maximum thickness dome of run 4 lies farther north.

The present-day ice-thickness distribution of run 3 (Fig. 5b) and run 4 (Fig. 6b) is now discussed. The $2000-2500 \mathrm{~m}$ thickness pattern of the Greenland ice sheet is more extended for run 3 than for run 4, due to sliding in the western part of the Greenland ice sheet caused by the temperate basal area in this region. In the northeast, the ice-thickness gradient of run 4 is steeper than that of run 3 ; here the cold basal ice hampers the ice flow. Both runs simulate a Tibetan ice sheet at the present day, which is unrealistic. Clearly, the model is unable to warm up the Tibetan Plateau once it is covered by ice or snow.

\section{CONCLUSIONS}

We showed that the choice of enhancement factor is crucial for the temporal development of the Northern Hemisphere ice cover if the response of the climate system is treated with the LLN model. We also showed that there are model setups leading to approximately the same ice cover through time for the vertically integrated and for the thermomechanical model. The thermomechanical model contains additional parameters (e.g. the geothermal heat and the sliding coefficient), which are poorly known and can be used to improve the modelling of ice cover through time in detail. Our computations show that the surface mass balance is an important factor in the simulation of the main features of ice cover through the last glacial-interglacial cycle. The discrepancies (e.g. too much ice in Siberia and too little in North America) can probably be avoided by forcing with a more realistic and geographically explicit climate model. On the other hand, the reaction of the cryosphere/climate system 
with the enhancement factor is so strong that the thermomechanics of ice could also have an important influence, because the ice flow depends on the temperature-dependent rate factor as well as on the enhancement factor.

\section{OUTLOOK}

To determine whether the thermomechanical model has essential advantages for paleoclimatic simulations, additional computations need to be carried out (e.g. sensitivity runs with varying geothermal heat and sliding parameter). These will elucidate the question how sophisticated the icesheet model should be for paleo runs and whether a proper representation of surface mass balance through time with a climate model is sufficient.

\section{ACKNOWLEDGEMENTS}

We would like to thank A. Berger for the opportunity to work in Louvain-la-Neuve, J.-F. Foccroule for supporting our work with the plot software, R. Greve for help and discussions, and $\mathrm{K}$. Hutter for permission to use the additional computer power of the Institute of Mechanics, Darmstadt, Germany.

\section{REFERENGES}

Calov, R. and K. Hutter. 1996. The thermomechanical response of the Greenland ice sheet to various climate scenarios. Climate Dyn., 12, 243-260. CLIMAP Project Members. 1981. Seasonal reconstructions of the Earth's surface at the last glacial maximum. Boulder, CO, Geological Society of America. (Map Chart MC-36.)

Deblonde, G. and W. R. Peltier. 1993. Late Pleistocene ice age scenarios based on observational evidence. f. Climate, 6(4), 709-727.

Gallée, H., J. P. van Ypersele, T. Fichefet, C. Tricot and A. Berger. 1991. Simulation of the last glacial cycle by a coupled, sectorially averaged climate-ice sheet model. 1. The climate model. 7. Geophys. Res., 96(D7), 13,139-13,161.

Greve, R. 1997. Application of a polythermal three-dimensional ice sheet model to the Greenland ice sheet: response to steady-state and transient climate scenarios. J. Climate, 10(5), 901-918.

Huybrechts, P. and J. Oerlemans. 1988. Evolution of the East Antarctic ice sheet: a numerical study of thermo-mechanical response patterns with changing climate. Ann. Glaciol., 11, 52-59.

Huybrechts, P. and S. T'siobbel. 1997. A three-dimensional climate-icesheet model applied to the Last Glacial Maximum. Ann. Glaciol., 25, 333-339.

Marsiat, I. 1994. Simulation of the Northern Hemisphere continental ice sheets over the last glacial-interglacial cycle: experiments with a latitude-longitude vertically integrated ice sheet model coupled to a zonally averaged climate model. Paleoclimates, 1, $59-98$.

Paterson, W. S. B. 1981. The physics of glaciers. Second edition. Oxford, etc., Pergamon Press.

Peltier, W. R. and S. Marshall. 1995. Coupled energy-balance/ice-sheet model simulations of the glacial cycle: a possible connection between terminations and terrigenous dust. 7. Geophys. Res., 100 (D7), 14,269-14,289.

Ritz, C., A. Fabre and A. Letréguilly. 1997. Sensitivity of a Greenland ice sheet model to ice flow and ablation parameters: consequences for the evolution through the Last Glacial cycle. Climate Dyn., 13,11-24.

Sellers, W. D. 1983. A quasi-three-dimensional climate model. f. Climate Appl. Meteorol., 22, 1552-1574.

Tarasov, L. and W. R. Peltier. 1997. Terminating the $100 \mathrm{kyr}$ ice age cycle. $\mathcal{J}$. Geophys. Res., 102(DI8), 21,665-21,693.

Tushingham, A. M. and W. R. Peltier. 1991. Ice-3G: a new global model of late Pleistocene deglaciation based upon geophysical predictions of post-glacial relative sea level change. 7. Geophys. Res., 96(B3), 4497-4523.

Weertman, J. 1964. The theory of glacier sliding. J. Glaciol., 5(39), 287-303. 